Family Medicine and Community Health

\section{Contributions and challenges of general practitioners in China fighting against the novel coronavirus crisis}

To cite: Li DKT, Zhu S. Contributions and challenges of general practitioners in China fighting against the novel coronavirus crisis. Fam Med Com Health 2020;8:e000361. doi:10.1136/fmch-2020-000361

DKTL and SZ contributed equally.

Received 16 March 2020 Accepted 16 March 2020

Check for updates

(c) Author(s) (or their employer(s)) 2020. Re-use permitted under CC BY-NC. No commercial re-use. See rights and permissions. Published by BMJ.

${ }^{1}$ World Organisation of Family Doctors (WONCA)

${ }^{2}$ General Practice Department, Zhongshan Hospital Fudan University, Shanghai, China

${ }^{3}$ Cross-Straits Medicine Exchange Association Committee of General Practice, China

Correspondence to

Professor Donald Kwok Tung Li; dr2318@hotmail.com

\section{INTRODUCTION}

As the World Health Organisation calls for urgent, aggressive actions to combat COVID19, China has been making positive contributions in the fight against the pandemic during the past few months. General practitioners (GPs) in China are at the forefront of tackling the spread of the virus. While the health sector in China has been under scrutiny globally, many articles have been disseminated within the country about the response. GPs in China hope that by sharing their experiences, international colleagues could benefit from what worked well and what went less well.

Coronavirus started spreading from Wuhan in Hubei Province in late 2019. As in many parts of China, Wuhan is a hospital-oriented health service, as the family medicine system is not yet fully implemented. The surge of patients to hospitals quickly overwhelmed the health system in Wuhan and surrounding towns and cities, as patients sought testing and treatment, and in the process helped to spread the virus more quickly. The experience has put the spotlight on the ineffectiveness of hospitals as the first port of call for this and other types of virus.

GPs working in the community are engaged in diagnosing and treating patients, educating the public and guiding the community in the fight against the outbreak. The main challenges for all healthcare providers, but for GPs in particular, are the overwhelming numbers of patients, the adverse working conditions-including exposure to infectious risks, the uncertainties and unknowns about the trajectory of the disease, and coping with fears and panic among the population. For GPs, the challenges do not end there: the continuity of care and treating the whole person rather than the single disease are essential inputs by GPs to lead the community to the path of recovery.
WHO led a Joint Mission to China in midFebruary 2020 where they commended the three-phase response established. As detailed in the WHO report, phase 1 of China's response was to prevent cases from spreading from Wuhan to other areas, to control the source of the infection, block transmission and prevent further spread. Phase 2 was to reduce the epidemic and slow the increases in cases, with all patients treated and close contacts isolated. Phase 3 focuses on reducing clusters of cases, thoroughly controlling the epidemic and striking a balance between epidemic prevention and control, and sustainable social and economic development. ${ }^{1}$

Community engagement is the first line of defence in the battle against infectious diseases. GPs are both gatekeepers and health promotors by empowering the community to build a firewall against the deadly virus. GPs are engaged in each of the three phases of response to the disease. For example, they help block the viral transmission in phase 1 by monitoring people at designated checkpoints, and they slow the increase of cases by treating patients and providing medical surveillance in the community in phase 2. In phase 3 , they take care of the clinical and psychological well-being of patients and extend that to their families, so the whole community can return to normal life, as soon as practical.

The various roles and contributions of GPs for the control of novel coronavirus as reported by some colleagues in China are discussed below.

Curbing the spread - guarding the checkpoints and protecting the community

Airports, railway stations and highways are cracks through which virus can spread; they are the front gates for preventing import of cases. GPs at the primary care level have been working around the clock with security staff to help guard the check points, where they 


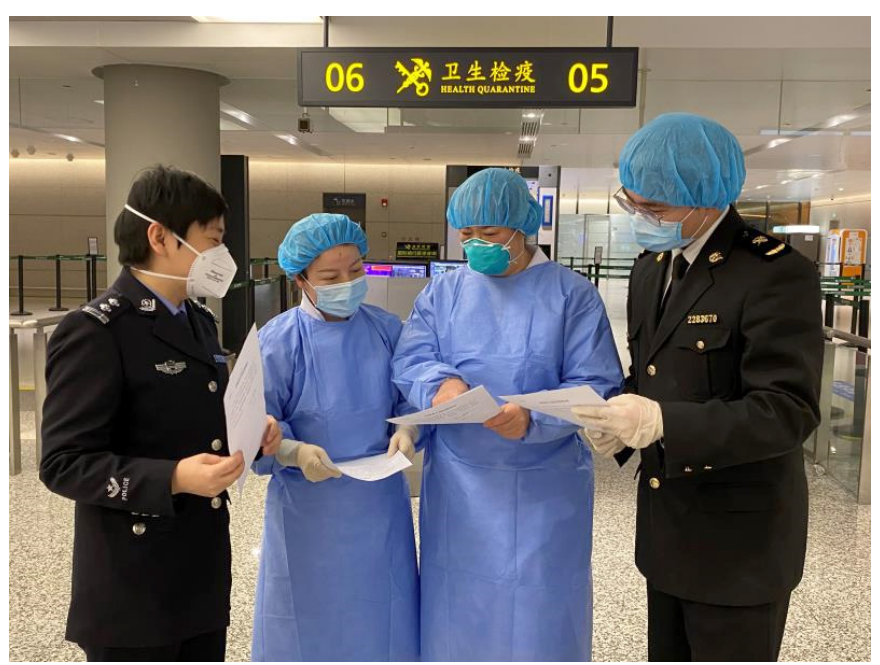

Figure 1 General practitioners at Shanghai Hongqiao Airport health checkpoints.

verify personal information and conduct health checks for travellers, refer suspected cases to hospitals for follow-up and assist epidemiological investigations (figure 1).

GPs also worked together with the local neighbourhood committees and community police in a 'Joint Defence Team' keeping the close contacts of confirmed cases and commuters entering regions under surveillance. The teams issue health warnings and give advice on legal obligations. They conduct daily health monitoring and provide psychological support. They provide advice to individuals under quarantine or medical surveillance on how to disinfect their homes and properly process their domestic waste. An example is the Xinjing Community Health Service Center in Changning District of Shanghai where GPs have been deployed to join the 'Defence Team'. The Chinese government provides designated isolation facilities for people who cannot secure accommodation

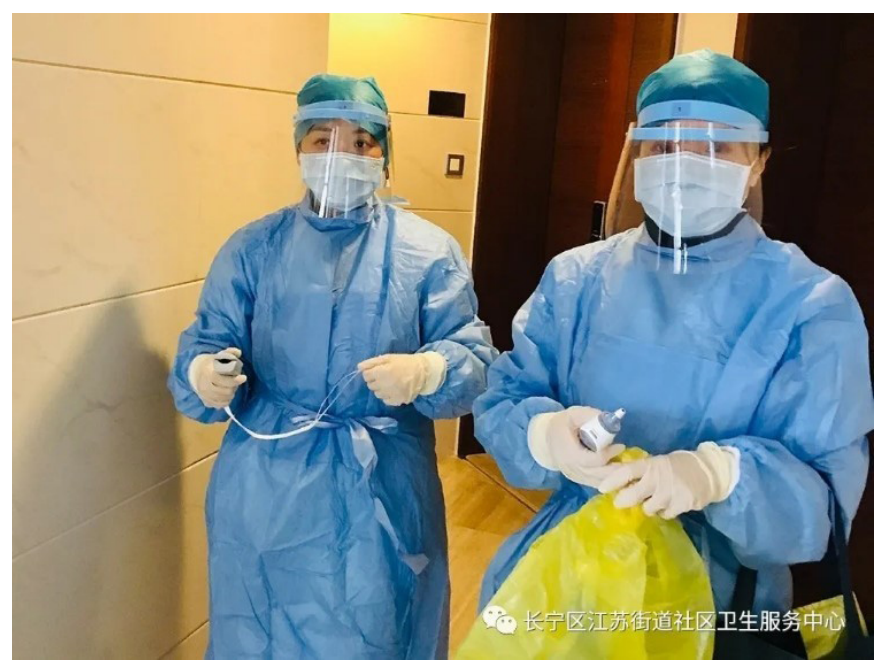

Figure 2 General practitioners from Jiangsu Street Community Health Service Center in Changning District of Shanghai disposing household wastes collected from isolated residents under medical surveillance as they work with other community workers in 'Joint Defence Teams'.

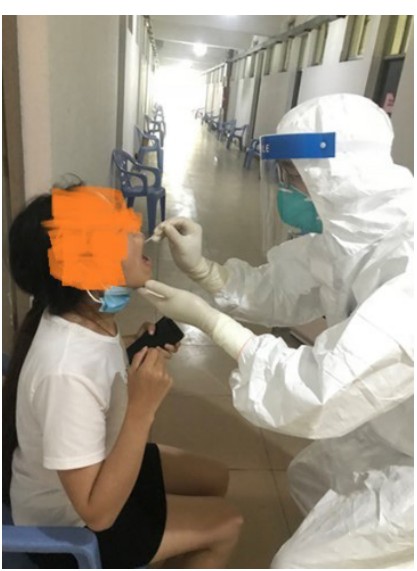

Figure 3 Dr Li Jierong, from Dongkeng Community Health Center in Dongguan City of Guangdong Province, collecting a nasopharyngeal secretion sample from a Hubei resident at an isolation facility.

during medical observation such as the Xinjing Community Health Service Center (figures 2 and 3).

\section{Detect and treat: from door to door}

Detecting cases at fever clinics

GPs provide points for sentinel surveillance. They are often the first to detect suspected cases and provide information to health authorities for contact tracing. During the novel coronavirus outbreak, GPs are seen everywhere: at fever clinics of different levels-from those in community health service centres to secondary and tertiary hospitals performing their duties in tracking and tracing patients.

The community health service centres have set up fever clinics according to scientific evidence and guidelines. A series of infection control measures and patient flow directions have been adopted to minimise the risk of cross infections. These centres not only provide services that meet the basic medical needs of patients but also provide surveillance to closely monitor potential infected cases (figure 4).
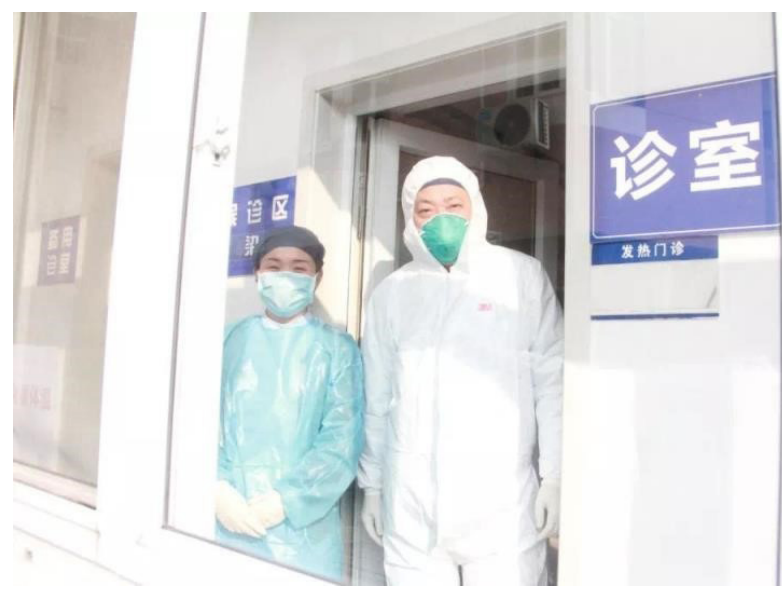

Figure 4 General practitioners at a fever clinic. 


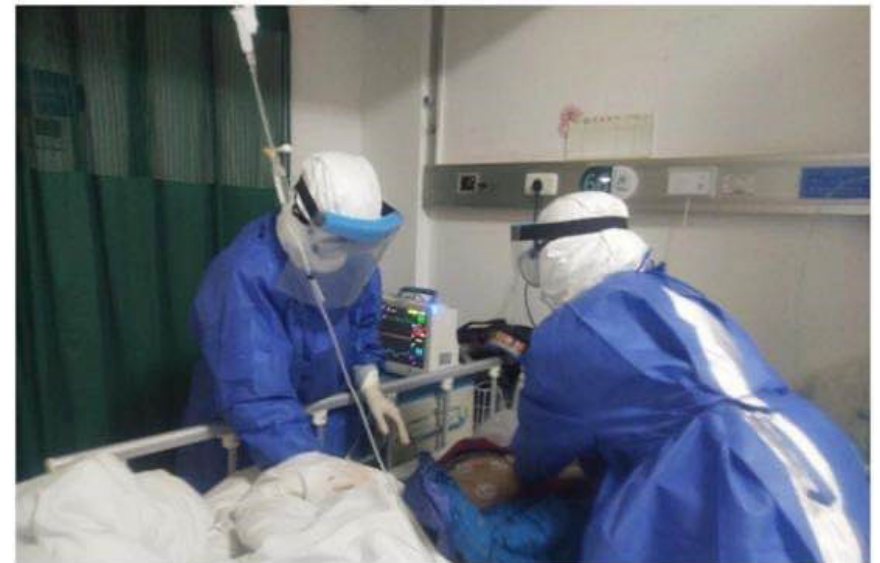

Figure 5 A medical team from Guizhou Province is the sixth medical aid team deployed to Hubei. Dr Xiao Xue (right) and her fellow teammate successfully resuscitated a cardiac arrest patient by applying external thoracic cardiac massage.

Treating the critically ill at the centre of the epidemic

GPs have reached out beyond the community to actively participate in the treatment of critically ill patients. In mid-February, Dr Xiao Xue from the General Medicine Department of Zun Yi Medical University Hospital volunteered to join a medical team in Guizhou Province, the sixth medical aid team that reached out to provide assistance to Hubei. This team took over the management of severe respiratory wards at a hospital in central Ezhou city of Hubei province. Dr Xiao and her colleagues engaged themselves to help treat patients right in the centre of the epidemic. They helped manage the severe respiratory symptoms caused by the novel coronavirus as well as the patients' other comorbidities while providing counselling for the patients' psychological problems. Their professionalism and dedication earned the trust and appreciation of many patients and the general public (figure 5).

\section{Providing continuity of care to discharged patients and the} chronically ill

For the past decade, China has been making efforts to strengthen its primary healthcare. The country launched a new round of healthcare reform in 2009 to strengthen primary healthcare and established and incorporated general practice and family medicine into the system. The State Council issued the Guidance on Establishing a General Practitioners System in 2011 and Guidance on the Promotion of Family Practice Contract Services in 2016. It aims to extend family practice contract services to the entire population by $2020 .^{2}$ Shanghai started experimenting with a family doctor programme in 2011. The programme was rolled out to other parts of China during the subsequent years. Under the system, families sign contracts with GPs who offer continuous one-on-one service for patients, providing health consultations and basic medical care. ${ }^{3}$

The signing of contracts with the GP system has shown its merit during the latest outbreak. Contracted GPs provide continuous care to patients recovering from coronavirus infections in their 14 days of rehabilitation and home care period after discharge. They monitor the patient's health by visiting them twice a day, continue to manage their existing morbidities as well as ease their anxiety through counselling. They also support the patients' families and neighbours, and seek assistance from hospitals and health authorities only when problems could not be dealt with at the community level.

During the epidemic, chronically ill patients have to endure many inconveniences in their daily lives. GPs are the ones who help them overcome many of those barriers by individual, personalised services catered to their needs. For example, GPs used to issue 1-month prescriptions but now they issue 3-month supplies instead so the patients do not need to return frequently for medication. Communication tools such as WeChat has been used for online prescriptions, and medicines can then be delivered door to door to those in affected areas.

GPs also maintain their outreaching home visit services to stable patients with chronic diseases under the established home-based medical care in the community even during the epidemic (figure 6).

\section{Exploring new modes of care: online health platforms}

GPs are in a good position in establishing community networks. Through their knowledge of the local community and their role as primary care service coordinators, they can work together with local neighbourhood committees to create health screening networks, which can provide contact tracing and the investigation of the sources of infections. These networks led by the GPs contribute significantly in the data gathering, epidemiological investigations and efforts in preventing further disease transmission.

GPs are using instant messaging tools such as WeChat, community broadcasts and electronic display boards to disseminate information and mobilise local residents and volunteers in public health duties such as disinfection and sanitisation. GPs also help promulgate public health messages such as reminding the public to avoid social gatherings and visits, personal hygiene awareness, proper ways of using masks, hand washing and the importance of good household ventilation. They also provide timely psychological counselling and support to the community, to counter fears and panic.

Calming fears is as crucial as stopping the spread of virus. GPs with comprehensive knowledge about the community and trained to have good communication skills have actively participated in online medical care platforms and counselling by phone and internet. Some GPs have produced videos on health tips or participated in interactive TV or online programs. These can alleviate anxiety and minimise unnecessary medical consultations. People suffering with minor ailments can consult the online doctors especially when they cannot go for a consultation in person for various reasons such as accessibility or isolation requirements (figure 7). 


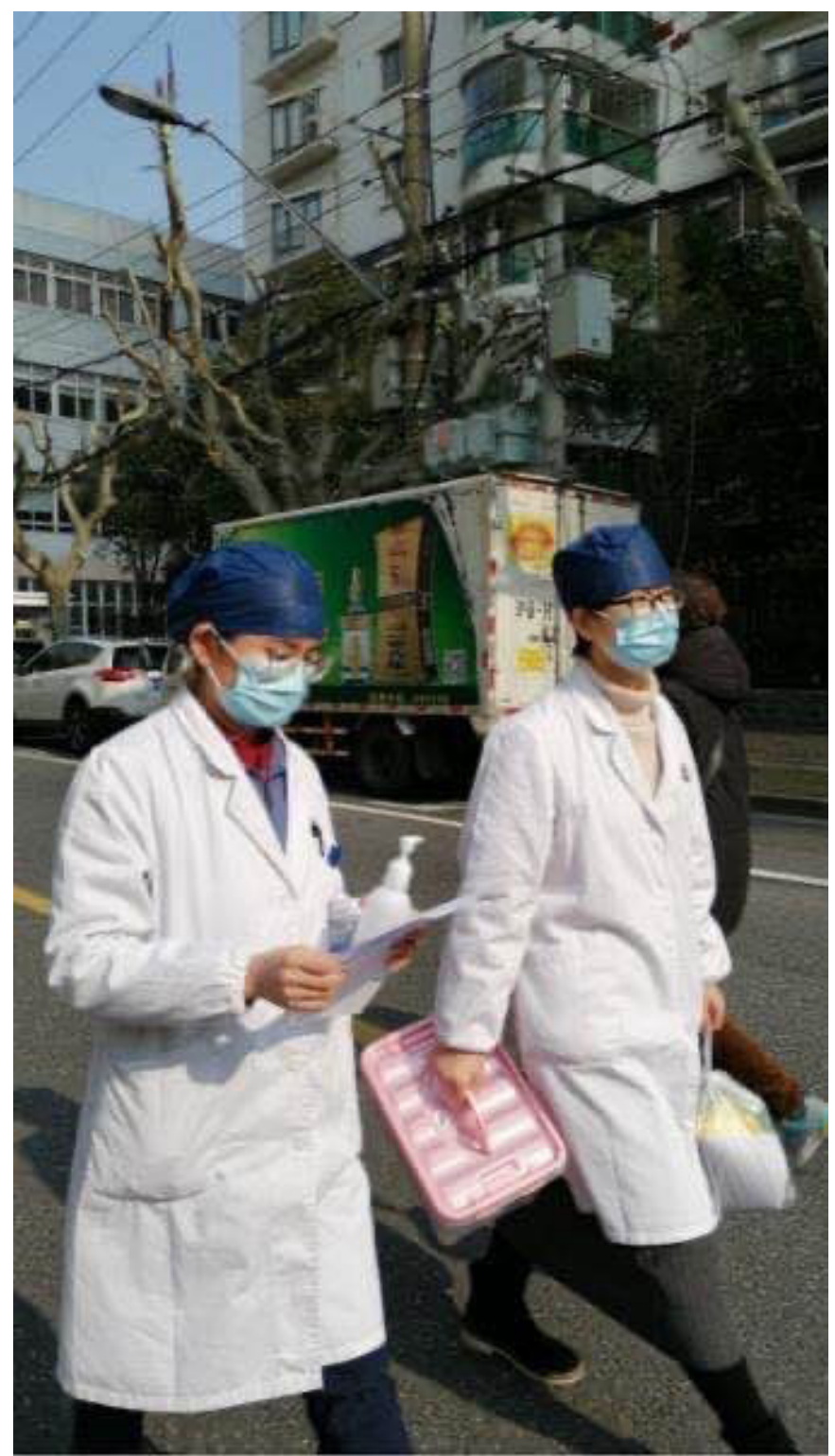

Figure 6 Dr Zhu Lan, from Xietu Street Community Health Service Center in Shanghai, delivering medicines to patients from door to door.

\section{ANALYSIS AND DISCUSSION}

The novel coronavirus outbreak is a critical moment for China and also for its healthcare workers. There are numerous instances of individual and team responses to the outbreak, many of them reflecting on the efforts of GPs who have developed trust and good communication with their patients. Providing both personal care and online support has helped to alleviate the inevitable anxiety, which can quickly take hold in communities.

In 2016, the Chinese State Council issued guidance on the promotion of Family Medicine, with the aim of extending availability of family practice to the entire population by $2020 .{ }^{23}$ This has not been fully implemented but is well under way. As the health system responded to the rapid spread of the coronavirus outbreak, the efforts and professionalism of GPs has been widely acknowledged and reported in the Chinese press. The COVID-19 outbreak

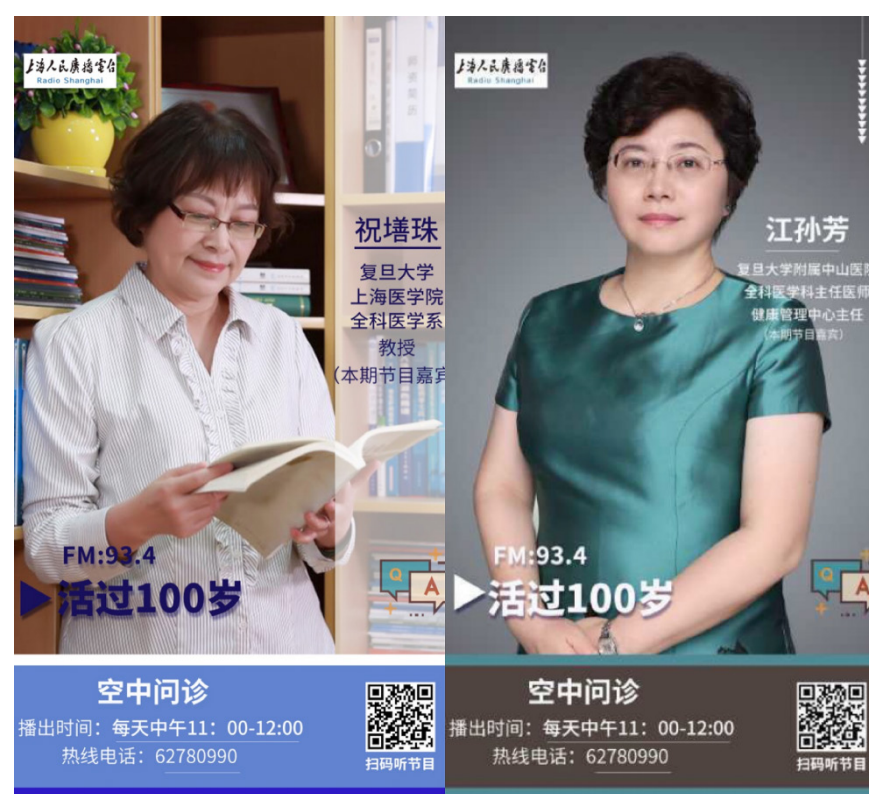

抗击新型冠状病毒特别节目抗击新型冠状病毒特别节目

Figure 7 Professor Zhu Shanzhu and Chief Doctor Jiang

Sunfang from the Department of General Medicine of Zhongshan Hospital, Fudan University, joined a TV health programme of Shanghai People's Broadcasting Radio.

has refocused attention on the 'first in last out' role of the GPs and has reinforced the effort for widespread availability of qualified GPs across the country. Through remarkable individual and team efforts, displaying truly professional general practice, the role of family medicine in the Chinese health sector is now well recognised. GPs have demonstrated remarkable contributions to all the three stages of response as advocated by WHO. It is worth mentioning again that GPs are in the best position to care for patients with emotional distress arising from outbreaks, such as post-traumatic stress disorder, which would be as devastating as physical health problems. Patients will not feel stigmatised by seeking help from someone they trust.

There are good lessons to be learnt from every outbreak and crisis that should not be wasted. As the outbreak is beginning to come under control in the country, the challenge ahead for the GPs and the healthcare system as a whole is refocused on how to promote people-centred integrated care in China.

The competence and trustworthiness of the GPs are most important. GPs are the primary healthcare coordinators. They work together with other professionals and authorities to ensure appropriate actions are taken promptly to reduce risks. Challenges of appropriate referral, triage and maintaining an effective tiered healthcare system remain. Putting resources into training GPs, giving due recognition to their skills through well-placed accreditation systems should be the way ahead. Once the trust is established, patients' health-seeking behaviour will also be changed. They will trust their family doctors to refer their problems to other healthcare professionals 
or hospitals only when necessary. Recognising and promoting the role of GPs in public health can also help fill the gap in population health services. The government and the public can then invite GPs to contribute to public health policies as well as working closely with the Central Disease Control system.

GPs are committed to leading the primary healthcare teams to combat the outbreak. They have a common wish to see patients return home from hospitals, and they will continue to take care of them.

Acknowledgements The authors thank $\mathrm{Dr}$ Hao Wu, the Director of Fangzhuang Community Health Service Center, Capital Medical University, and Dr Qiao Jianrong, the WHO Coordinator of Health Systems and Health Security for help in preparing the paper.

Funding The authors have not declared a specific grant for this research from any funding agency in the public, commercial or not-for-profit sectors.

Competing interests None declared.
Patient consent for publication Not required.

Provenance and peer review Commissioned; internally peer reviewed.

Open access This is an open access article distributed in accordance with the Creative Commons Attribution Non Commercial (CC BY-NC 4.0) license, which permits others to distribute, remix, adapt, build upon this work non-commercially, and license their derivative works on different terms, provided the original work is properly cited, appropriate credit is given, any changes made indicated, and the use is non-commercial. See: http://creativecommons.org/licenses/by-nc/4.0/.

\section{REFERENCES}

1 Who.int, Available from. Report of the WHO-China Joint Mission on Coronavirus Disease 2019 (COVID-19) [Internet], 2020. Available: https://www.who.int/docs/default-source/coronaviruse/who-chinajoint-mission-on-covid-19-final-report.pdf [Accessed 16 Mar 2020].

2 Li L, Zhong C, Mei J, et al. Effect of family practice contract services on the quality of primary care in Guangzhou, China: a cross-sectional study using PCAT-AE. BMJ Open 2018;8:e021317.

3 Chinadaily.com.cn. Family doctors the future of China's healthcare system [Internet], 2020. Available: https://www.chinadaily.com.cn/ china/2016-02/26/content_23657040.htm [Accessed 16 Mar 2020]. 


\section{Correction: Contributions and challenges of general practitioners in China fighting against the novel coronavirus crisis}

Li DKT, Zhu S. Contributions and challenges of general practitioners in China fighting against the novel coronavirus crisis. Fam Med Com Health 2020;8:e000361

Since the online publication of the article, the authors noted some errors that have since been updated in the HTML and PDF versions of the article. The changes have been listed below:

1. Affiliations were conflated and listed with the incorrect geographical location

2. Authors should have been listed with equal contribution

3. The opening sentence has been changed from 'China was the first country where the novel coronavirus appeared.' to 'As the World Health Organisation calls for urgent, aggressive actions to combat COVID-19, China has been making positive contributions in the fight against the pandemic during the past few months.'

Open access This is an open access article distributed in accordance with the Creative Commons Attribution Non Commercial (CC BY-NC 4.0) license, which permits others to distribute, remix, adapt, build upon this work non-commercially, and license their derivative works on different terms, provided the original work is properly cited, appropriate credit is given, any changes made indicated, and the use is non-commercial. See: http://creativecommons.org/licenses/by-nc/4.0/.

C Author(s) (or their employer(s)) 2020. Re-use permitted under CC BY-NC. No commercial re-use. See rights and permissions. Published by BMJ.

Fam Med Com Health 2020;8:e00361corr1. doi:10.1136/fmch-2020-000361corr1

Check for updates 